\title{
Inclusão Digital e o Ensino de Matemática em Escolas Públicas: Vivências no Programa Infomat/Proext
}

\author{
Edileide dos Santos Alves ${ }^{1}$, Cibelle de Fátima Castro de Assis ${ }^{1}$, Fagner Silva Martins ${ }^{1}$ \\ ${ }^{1}$ Universidade Federal da Paraíba (UFPB) \\ Caixa Postal 117 - 58.297-000 - Rio Tinto - PB - Brasil \\ edileidematematica@gmail.com, \{cibelle,fagner.silva\}@dce.ufpb.br
}

\begin{abstract}
Technology is increasingly present in schools, it's needs to adapt to this reality once these tools can contribute to the processes of teaching and learning and the teachers must to be motivating to change their traditional way of teaching and encouraging their student to be more interested in studies. This article discusses actions for inclusion of digital resources in teaching math from the experience of two students under the PROEXT with the project Infomat Digital Inclusion in Mathematics Teaching in Public Schools of North Coast of Paraiba, held during the year 2014. It brings contributions to understando the school reality and challenges of an inclusive process in these places.
\end{abstract}

Resumo. A tecnologia está cada vez mais presente nas escolas. Este fato tem provocado a necessidade de adaptá-las à esta realidade uma vez que essas ferramentas podem colaborar para os processos de ensino e aprendizagem motivando os docentes a mudarem seu método tradicional de ensino e incentivando o interesse dos alunos pelos estudos. O presente artigo discute ações de extensão universitária para inclusão de recursos digitais no ensino de matemática a partir da experiência de dois alunos no âmbito do PROEXT com o projeto InfoMat - Inclusão Digital no Ensino de Matemática em Escolas Públicas do Litoral Norte da Paraíba, realizado no ano de 2014. Traz contribuições sobre a realidade escolar e desafios de um processo de inclusão nesses espaços.

\section{Introdução}

As Tecnologias de Informação e Comunicação (TICs) são indispensáveis na sociedade atual e ao mesmo tempo têm exigido competências como a resolução de problemas diários, aprendizado contínuo e capacidade de trabalho em grupo. Ela também é indispensável hoje em sala de aula, pois a escola precisa encontrar novas formas de ensino e aprendizagem para que possa preparar o cidadão para o mundo moderno. Os avanços científicos e tecnológicos promovem o repensar sobre os métodos de ensino que desenvolvam novos desafios e situações para os jovens estudantes.

As TICs têm sido vistas por diversos pesquisadores como ferramentas capazes de facilitar a aprendizagem dos alunos propiciando discussões e análises críticas para construção do conhecimento. Diante dessa realidade os softwares podem ser um excelente recurso para auxiliar o professor no desenvolvimento de uma proposta de ensino inovadora e mais dinâmica, como também pode contribuir para que o aluno adquira conceitos em determinadas áreas do conhecimento de forma mais objetiva, pois estas ferramentas são capazes de proporcionar um estudo mais detalhado e representativo levando os alunos a uma aprendizagem mais significativa. 
No ensino da Matemática os softwares educacionais apresentam-se como uma alternativa que pode proporcionar um aprendizado neste sentido, uma vez que os alunos podem experimentar hipóteses, desenvolver o seu raciocínio lógico e a criatividade, ter maior interatividade, mais participação, construção do próprio conhecimento, além de que a matemática pode passar a ser considerada como uma matéria interessante, fazendoos perceber sua importância não só em sala de aula como no cotidiano, contribuindo para um maior interesse sobre essa disciplina.

Segundo as OCEM [Brasil 2006], os softwares no ensino de Matemática apresentam recursos que provocam de forma muito natural, o processo que caracteriza o "pensar matematicamente", ou seja, os alunos fazem experimentos, testam hipóteses, esboçam conjecturas, criam estratégias para resolver problemas. No entanto, para o bom uso de um software ou de qualquer recurso no ambiente escolar, além de conhecer o objeto matemático de estudo, a estrutura disponível na escola, faz-se necessário ter clareza sobre a adequação da proposta e quais conhecimentos prévios dos alunos serão acionados com objetivo de aprendizagem. O professor deverá, segundo [MISKULIN 2009], considerar características computacionais e educacionais, e deverá identificar quais as suas possibilidades e limitações.

Neste contexto, o referente trabalho apresenta o relato da experiência de dois alunos, sendo um do curso de Licenciatura em Matemática e o outro do curso de Licenciatura em Ciência da Computação no desenvolvimento do programa de extensão universitária PROEXT com o projeto Inclusão Digital no Ensino de Matemática em Escolas Públicas do Litoral Norte da Paraíba, durante o ano de 2014. O objetivo principal do programa foi promover a inclusão de recursos digitais no ensino de Matemática nas escolas da rede pública do município de Rio Tinto por meio de ações que fortalecessem o exercício da prática docente integrando a Universidade à comunidade.

\section{Fundamentação Teórica}

As tecnologias de informação e comunicação desde muito tempo fazem parte das escolas e vem se investindo cada vez mais nesse tipo de recurso para a Educação. Porém, muitas vezes, as instituições não utilizam os recursos que possuem, tampouco os professores se sentem preparados para utilizá-los em suas salas de aula. É necessário que eles estejam preparados para atuar nesse novo contexto e promovam essa forma de aprendizagem. [LEITE and SAMPAIO 1999] mostram que todas estas mudanças têm exigido que o professor altere questões operacionais e epistemológicas e crie novas formas de organização das aulas, pois o professor precisa ser estimulado a atuar neste novo cenário.

Sabe-se que nos últimos quarenta anos, o computador vem sendo considerado o mais versátil mediador tecnológico no campo da Educação, feito este que se deve aos softwares [Jucá 2011]. Os softwares tem sido vistos, atualmente, como meios que podem propiciar ao aluno uma maior interação com o conhecimento e podem possibilitar que os mesmos possam aprender em seu próprio ritmo, através da construção do seu conhecimento. A interação social é uma característica importante em sala de aula, faz com que os alunos participem exercendo influência significativa uns sobre os outros e o dinamismo dos softwares faz surgir uma nova identidade entre os alunos e o computador, contribuindo para desafiá-los à realização das atividades. De acordo com [Zimmerman and Schunk 2001], a aprendizagem é uma atividade que deve ser realizada 
pelo próprio indivíduo de modo pró-ativo, sendo necessário que ele desenvolva estratégias para o planejamento e organização de suas atividades de aprendizagem.

A utilização dos softwares em sala de aula deve ser norteada por interesses pedagógicos e não apenas como um mero recurso ou para propor uma aula diferente, ou ainda porque os alunos gostam de computadores, com isso a mediação do professor desempenha um papel importantíssimo e determinante. Segundo [MISKULIN 2009], "o ambiente, por mais rico e construtivo que seja, por si só, não é suficiente para promover contextos propícios à exploração e construção do conhecimento, no contexto tecnológico" (p.165).

Muito tem sido pesquisado acerca da contribuição da utilização de materiais instrucionais digitalizados como meio para apoiar o processo de aprendizagem, denominados de objetos de aprendizagem como evidenciam as pesquisas de Park, Lee e Kim (2009). Segundo Petters (2006), a digitalização do ensino e da aprendizagem possibilita simulações que favorecem a aprendizagem por descoberta. Dessa forma, o professor assume o importante papel de orientador e mediador do processo de aprendizagem dos alunos. Por mediação pedagógica entendemos a atitude, o comportamento do professor que se coloca como um facilitador, incentivador ou motivador da aprendizagem e que se apresenta com a disposição de ser uma ponte entre o aprendiz e sua aprendizagem [Masetto 2000]. Uma ponte dinâmica, e que, por isso mesmo, utiliza-se de inúmeros recursos para colaborar ativamente no alcance dos objetivos de aprendizagem dos seus estudantes.

A inserção de tecnologias digitais na educação por si só não provoca mudanças. Muitas são as pesquisas já realizadas sobre a utilização da tecnologia na educação, porém é importante destacar que esses estudos nem sempre tem chegado nas salas de aulas das escolas [Castro Filho 2007]. Dessa maneira, é importante conhecer e analisar o contexto escolar, buscando identificar suas necessidades e capacitar os professores para que os mesmos possam utilizar os recursos de modo a favorecer o aprendizado de seus alunos. Para [Freire 1996] é importante que a formação docente esteja voltada para uma prática construtiva, onde o formando, desde o princípio de sua experiência formadora, deve se assumir como sujeito também da produção do saber e se convencer definitivamente de que ensinar não é transferir conhecimento, mas criar as possibilidades para sua produção ou a sua construção. Essa abordagem implica numa nova proposta de formação. Formação de caráter construtivo, reflexivo, crítico, mas também de consciência de um processo sempre inacabado, que se refaz. Para [Perez 2004], a formação inicial deve proporcionar aos licenciandos um conhecimento gerador de atitude que valorize a necessidade de uma atualização permanente em função das mudanças que se produzem, fazendo-os criadores de estratégias e métodos de intervenção, cooperação, análise, reflexão e construção de um estilo rigoroso e investigativo.

Desta forma questionamos a realidade das escolas públicas brasileiras quanto aos processos de ensino e aprendizagem da Matemática através do uso de Tecnologias da Informção e Comunicação ao mesmo tempo em que buscamos investigar nesta realidade as condições de trabalho e elementos para a formação do professor para esta tarefa. 


\section{Objetivos Gerais}

Discutir ações da extensão para inclusão de recursos digitais no ensino de Matemática em escolas públicas promovidas pelo programa InfoMat.

\subsection{Objetivos Específicos}

- Apresentar as fases de desenvolvimento do programa de extensão universitária InfoMat/PROEXT;

- Contextualizar as ações do InfoMat e o envolvimento da comunidade escolar;

- Analisar as contribuições do InfoMat para a inclusão digital nas escolas participantes e para a formação do futuro professor de Matemática.

\section{Metodologia}

Com o objetivo de promover a inclusão digital através da utilização de recursos tecnológicos para o ensino de Matemática o programa InfoMat/PROEXT da Universidade Federal da Paraíba/Campus Iv foi desenvolvido durante o ano de 2014 em duas escolas públicas, uma pertencente à rede municipal e outra à rede estadual de ensino

A primeira ação delineada pelo projeto nas escolas foi ministrar uma palestra para os professores de Matemática e para os diretores. A palestra procurou motivar os docentes quanto aos benefícios que a informática pode trazer à educação matemática. Os responsáveis por esta palestra foram os professores da UFPB envolvidos no programa. Posteriormente foi feita uma pesquisa nas escolas por meio de questionários, os quais preparamos, aplicamos e posteriormente analisamos todos os dados coletados. Para essa pesquisa entrevistamos alunos de Ensino Fundamental e Médio, professores de Matemática e diretores das escolas. A pesquisa tinha os objetivos de identificar os conteúdos de maiores dificuldades para o processo de ensino e aprendizagem da matemática, traçar o perfil da utilização de informática pelas escolas, pelos professores e pelos alunos. A análise feita a partir desta pesquisa auxiliou na avaliação deste programa ao final de 2014, observando se as escolas ganharam mais experiências com o uso da informática para apoiar o ensino de Matemática.

Com base na pesquisa selecionamos os principais conteúdos citados como sendo fonte de dificuldades e realizamos diversas buscas e seleções de recursos digitais que podem auxiliar no aprendizado desses conteúdos. Para isso, utilizamos como base de busca sites governamentais como o Portal do Professor (http://portaldoprofessor.mec.gov.br/index.html), o RIVED (http://rived.mec.gov.br) e outros repositórios de materiais como o site do GeoGebra (http://www.geogebra.org/cms/). Por fim, acompanhamos professores das escolas na elaboração de sequências didáticas para as aulas em que seriam explorados recursos de TICs e auxiliamos esses professores durante a execução dessas aulas. Avaliamos a experiência junto aos alunos e professores por meio de questionários e pela análise do desempenho dos alunos em algumas atividades propostas e de sua participação e motivação nessas aulas.

A equipe deste projeto é composta por docentes qualificados na área de Matemática e Informática e de seus alunos de graduação. Divide-se em três professores de Licenciatura em Matemática, quatro de Ciência da Computação e Sistemas de 
Informação. Ao total participaram doze alunos bolsistas, sendo cinco de Licenciatura em Matemática, quatro de Licenciatura em Ciência da Computação e dois alunos de Sistema de Informação. Sabe-se que profissionais de Sistemas são capazes de desenvolver softwares, profissionais de licenciatura em computação sabem avaliar softwares educacionais e profissionais de licenciatura em Matemática conhecem bem as demandas específicas para a área de ensino da Matemática e técnicas de ensino dessa disciplina. Dessa forma, professores e alunos desses três cursos puderam trocar e vivenciar intensas experiências buscando contribuir com a sociedade e aprender com ela. Acredita-se também que a troca de experiências entre professores das escolas públicas e os estudantes de licenciatura em Matemática permite uma formação continuada à esses professores ao passo que traz grandes benefícios à formação profissional dos futuros professores aproximando-os da realidade educacional e da sociedade em que estão inseridos.

\section{Resultados}

Os resultados deste trabalho serão apresentados a seguir procurando divulgar e analisar o perfil das escolas, dos professores e alunos. Sabendo que cada escola possui características particulares, seus perfis serão apresentados separadamente.

\subsection{Perfil das Escolas}

A escola parceira do projeto pertencente a rede municipal, no ano de 2014 tinha 960 alunos matriculados nos turnos manhã e tarde, sendo composta por 95 funcionários e 10 professores de Matemática. Esta instituição de forma geral possui uma boa estrutura física, porém em se tratando da Informática, observou-se que o laboratório praticamente não existia, pois possuía apenas oito computadores em sua maioria desatualizados e sem possibilidade de uso, além de quê o espaço físico estava em péssimas condições.

A escola da rede estadual de ensino possuia 775 alunos matriculados entre os turnos matutino, vespertino e noturno. A equipe era composta por 95 funcionários e 5 professores de Matemática atuando na área. Em relação à sua estrutura física, podemos dizer que é bem estruturada e em relação ao seu laboratório de informática, ao contrário da escola citada anteriormente, era um espaço bem organizado com 19 computadores e atendia às necessidades dos alunos e professores da escola, sendo utilizados quase todos os dias segundo alguns docentes da instituição.

\subsection{Utilização de Informática Pelos Professores e Alunos das Escolas}

Para esta pesquisa foram entrevistados 13 professores de matemática e 475 alunos nas duas escolas. O questionário para os professores envolveu perguntas sobre o nível de formação, o uso de tecnologias no cotidiano e nas aulas de matemática. Para os alunos foram analisados a situação escolar deles, a importância da matemática no seu cotidiano, o uso de tecnologias e os conteúdos matemáticos de maiores dificuldades apresentados.

Observando as entrevistas com os professores de matemática concluiu-se quanto à formação que apenas um não possuia formação superior completa e os doze restantes possuíam pelo menos formação em Matemática e a maioria ensinava apenas a disciplina de Matemática.

Sobre o uso de tecnologias, constatamos que 12 destes professores possuíam computadores com acesso à internet em casa e todos os dias utilizavam deste recurso geralmente para editar textos, usar planilhas, acessar redes sociais ou sites de busca, entre 
outras utilidades. Resultados esses que demonstram que grande parte deles estão inseridos no contexto de inclusão digital, mas no decorrer da pesquisa veremos que eless não aplicam à sua atividade docente.

Apesar desses professores estarem inseridos no mundo tecnológico, 69\% afirmaram não utilizar o laboratório de informática para suas aulas de matemática, os principais fatores citados foram: as escolas não possuem computadores suficientes para todos os alunos, a falta de recursos para se trabalhar, a dificuldade dos alunos com a informática e a falta de preparação dos mesmos para utilizar a tecnologia em suas aulas. Os poucos professores destas escolas que relataram utilizar o laboratório de informática disseram utilizar semanalmente e que além de utilizar a internet como meio de incentivar a pesquisa também usam alguns softwares educativos com os alunos como, por exemplo, o GeoGebra. Acreditamos que a falta de equipamentos realmente é lastimáve.

Em relação a softwares instalados nos computadores das escolas, percebeu-se que apenas o GeoGebra foi citado pelos docentes e que a maioria demonstrou não saber que outros aplicativos estavam instalados nestas máquinas. Com isso, vimos a necessidade de que estas instituições sejam incluídas no mundo da informática atendendo alunos e os professores.

Sobre a utilização de tecnologias por parte dos alunos, a pesquisa atingiu 23 turmas de ensino fundamental e médio. A maioria desses estudantes não possui computador em casa, mas têm algum tipo de dispositivo móvel dos quais muitos têm acesso à internet, os que têm computadores relataram utilizá-lo para algumas atividades cotidianas como podemos ver na figura 1.

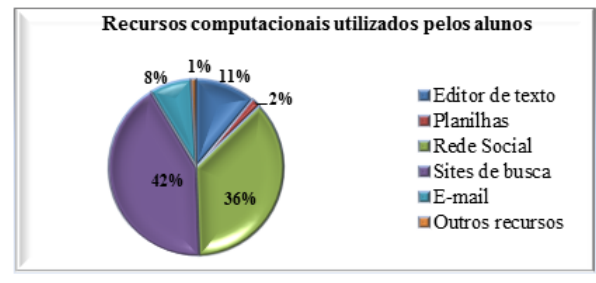

Figura 1. Recursos computacionais

Observando a figura 1 temos que sites de busca e rede social são os recursos mais utilizados por estes alunos em seu cotidiano. Infelizmente, os recursos editor de texto, planilhas e e-mail não tiveram uma porcentagem tão ampla, significando que possivelmente eles utilizam o computador mais como um meio de entretenimento do que um recurso para ampliar seu nível de aprendizagem. Sabemos que a utilização de planilhas como o Excel é um excelente recurso para aprimorar os estudos, inclusive a aprendizagem da Matemática.

Boa parte dos alunos que possuem dispositivos móveis usa o sistema operacional Android e utilizam os equipamentos para algumas atividades as quais veremos na figura 2.

Através da figura 2, podemos perceber que a maioria destes estudantes utilizam seus dispositivos móveis para ter acesso à internet e poucos utilizam dela para realizar pesquisas. Ainda observamos que funções como fazer ligações, receber e enviar mensagens e jogar também são bem utilizadas pelos alunos, porém os jogos citados por eles não 
CBIE-LACLO 2015

Anais do XXI Workshop de Informática na Escola (WIE 2015)

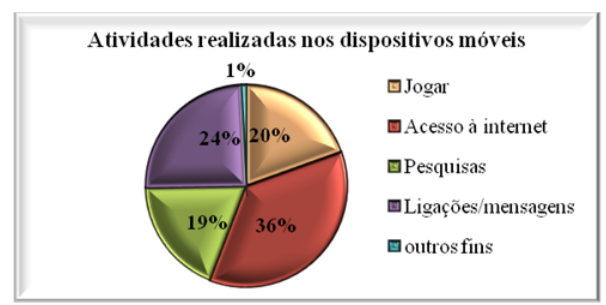

Figura 2. Atividades realizadas nos dispositivos móveis

incluem jogos educativos. A respeito da utilização do laboratório de Matemática nestas escolas, temos que infelizmente apenas 58 alunos já participaram de alguma aula no laboratório e apenas 15 já utilizaram algum software matemático, um número bem inferior ao total de alunos entrevistados. Fazendo-nos refletir o quão é importante trazer este trabalho para as escolas, com o intuito de incentivar a inclusão digital. .

\subsection{Os interesses dos alunos pela Matemática e os conteúdos de maiores dificuldades}

Sabendo que a Matemática é uma disciplina que grande parte dos estudantes têm dificuldades de aprendizagem, resolvemos conhecer o que os alunos destas instituições pensam sobre ela.

Temos que mais da metade 55\% destes estudantes disseram gostar mais ou menos de Matemática, não sabendo explicitar exatamente se gostam ou não, $14 \%$ dos alunos disseram que não gostam e $31 \%$ que gostam. A maioria deles apresenta dificuldades nesta matéria escolar e apontando os seguintes conteúdos como suas fontes de dificuldades: Quatro Operações, Raiz quadrada, Conjunto dos números inteiros, Potenciação, Números racionais, Equação do $1^{\circ}$ e $2^{\circ}$ grau, Geometria Analítica, Funções, Probabilidade, reptresentação com algarismo romanos, Frações, Álgebra e ainda houve alunos que rrelataram possuirem muitas dificuldades em resoluções de problemas diversos.

A grande quantidade de conteúdos apontados por estes alunos nos impressionou, principalmente pelo fato de que a maioria destes conteúdos pertence a séries anteriores nos levando a repensar no déficit que a maioria traz em seu currículo desde séries iniciais, atrapalhando no rendimento escolar das séries atuais. Outro fato que nos chamou atenção foi que $38 \%$ dos alunos entrevistados não entendem que a Matemática tem inúmeras relações com o cotidiano, ou seja, um número grande de alunos revelou a concepção de que a Matemática não é essencial no nosso dia a dia e que não faz parte dele constantemente, fato esse preocupante.

\subsection{Apoio Pedagógico aos professores das Escolas}

As atividades nas escolas foram realizadas no laboratório de informática junto com os professores de Matemática. Tivemos suporte de um data show, computadores do laboratório, notebooks e tablets disponibilizados pelo projeto. Todas as aulas foram marcadas e planejadas com antecedência juntamente com os professores das escolas. Para cada planejamento foi considerado o conteúdo que o professor estava abordando no momento em sala de aula ou outro conteúdo que ele achasse necessário que seus alunos revissem. Dependendo do conteúdo selecionado, foram feitas diversas pesquisas de aplicativos e recursos digitais matemáticos que fossem capazes de suprir o objetivo de cada aula pela 
equipe do InfoMat. Dessa forma as aulas e as atividades eram elaboradas conforme cada tipo de recurso que seria utilizado e todas as propostas procuraram trabalhar atividades que além de conter conteúdos matemáticos que eram fonte de dificuldades para os alunos, pudesse também trabalhar com eles a diversidade de potencialidades dos aplicativos.

Por exemplo, uma das aulas teve como tema o estudo da Função Quadrática utilizando o software matemático GeoGebra. Esta aula foi planejada para alunos de $1^{\circ}$ ano do Ensino Médio e atingiu 5 turmas com um total de 95 alunos participantes. O objetivo da aula era compreender o conceito de Função Quadrática, as reptresentações analíticas e gráficas utilizando o software matemático de forma que os alunos percebessem visualmente a relação dos coeficientes e os diferentes comportamentos da Função. Uma das atividades abordadas no tema citado acima foi a atividade 1, à seguir, onde buscou-se observar as diferentes parábolas apresentadas no GeoGebra procurando identificar as características pertencentes a cada uma. Ou seja, observar a concavidade, vértice e intersecções através da movimentação feita nos diferentes gráficos à medida que cada coeficiente era alterado a partir dos seletores. Apresenta-se na figura 3 uma construção desta atividade no software Geogebra.

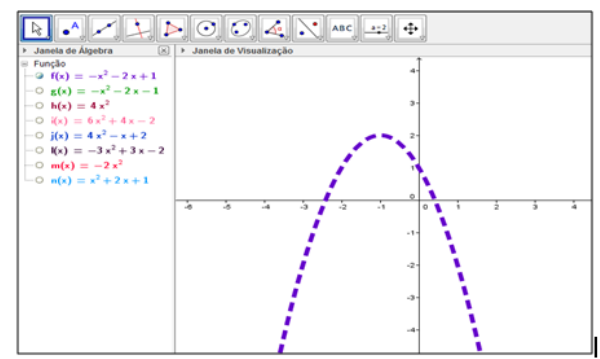

Figura 3. Construção da atividade 1 no Geogebra

Outra aula tratou de Sistemas de Equações utilizando o software matemático GeoGebra, desenvolvida com alunos do $7^{\circ}$ ano para um total de 4 turmas tendo uma média de 65 alunos participantes. Esta aula teve como objetivo identificar, modelar e resolver sistemas de equações do $1^{\circ}$ grau através de representação geométrica e problemas com contextos do cotidiano. Um exemplo de atividade abordada nesta aula foi a atividade 2, na qual através de situações problemas, os alunos deveriam encontrar o sistema de equações que representa a situação e em seguida inseri-lo e resolvê-lo geometricamente no GeoGebra. Buscou-se Incentivar os alunos a descrever os procedimentos usados em cada etapa e como eles perceberam os diferentes resultados apresentados no aplicativo. A construção desta atividade no Geogebra encontra-se na figura 4.

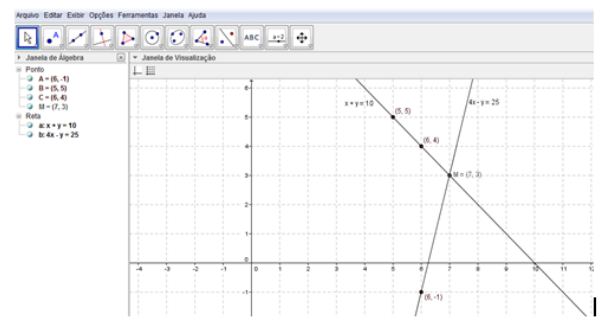

Figura 4. Construção da atividade 2 no GeoGebra 
As aulas exigiam que alunos e os professores conhecessem e manuseassem algumas ferramentas presentes na tela principal do software e que, de forma dinâmica e visual, analisassem passo a passo as construções feitas. A partir das aulas realizadas, foi possível perceber aspectos gerais sobre o uso destes recursos por estudantes e professores.

Primeiramente foi observado que apesar de alguns professores não utilizarem softwares educacionais em suas aulas, mesmo assim não apresentaram muitas dificuldades em manusear alguns aplicativos utilizados, como por exemplo com o Geogebra. Porém percebeu-se por parte de alguns a inquietação em estar trabalhando com um método que exige mais paciência no processo de raciocínio do aluno, pois com esses tipos de recursos o aluno passa a enxergar a Matemática de uma maneira diferente do convencional e esse processo exige do professor compreensão em entender que o trabalho realizado pode levar um pouco mais de tempo do que o habitual.

Por parte dos alunos, ficou claro que a maioria possui muitas dificuldades em manusear algumas teclas do computador e que realmente possuem dificuldades em Matemática como já foi mencionado anteriormente. Mesmo assim, o manuseio dos softwares ou jogos utilizados nas aulas não foram considerados difíceis por eles e as poucas dificuldades apresentadas eram sanadas a todo momento no decorrer das atividades, inclusive pelos próprios colegas.

Os alunos demonstraram um déficit grande de conhecimento em relação à Matemática, pois foi visto que aparentemente estão acostumados a realizar uma matemática mecânica onde os professores normalmente apresentam o conceito, um exemplo e uma atividade com base no exemplo dado. Á medida que os aplicativos foram utilizados percebeu-se que o raciocínio lógico deles demoravam para chegar as conclusões esperadas, mostrando com isso que de certo modo as aulas foram válidas desde que puderam mostrar para o professor a importância de uma nova metodologia tanto como estímulo para a disciplina como para fazer o aluno aprender de um modo diferente do que convencionalmente vem sido trabalhado.

\section{Considerações Finais}

Através dos diversos dados coletados entendemos que mesmo alunos e professores estando inseridos no mundo tecnológico não estão utilizando destes recursos para aprimorar seus conhecimentos em Matemática e não utilizam softwares matemáticos educativos no cotidiano, mostrando a necessidade de incentivar a inclusão digital na escola e na Educação Matemática.

Sabemos que o uso de recursos digitais podem solucionar problemas encontrados no âmbito educacional, mas acreditamos que se vivenciada em sala de aula pode provocar a motivação da aprendizagem e a ruptura da postura passiva do aluno, contribuindo inteiramente para a instrumentalização no processo de ensino e aprendizagem, para dar condições e suporte necessário aos alunos e professores, no sentido de enriquecer suas ações pedagógicas.

Faz-se necessário incentivar os professores na mudança de suas aulas, pois como vimos neste trabalho grande parte disse nunca ter utilizado um laboratório de informática. Devemos fazê-los entender que recursos como os que foram propostos ajudam o aluno perceber de maneira mais simples e estimulante e o quanto a Matemática é interessante e importante em nosso dia a dia. 
O trabalho desenvolvido no InfoMat, como experiência profissional foi muito gratificante, pois a cada visita feita à escola pode-se conhecer na realidade como funciona uma instituição de ensino. Passamos a nos reconhecer como docente e como pesquisadora, observando como poderíamos nos aperfeiçoar a cada dia e o que poderia ser feito para contribuir com o progresso do ensino da Matemática com uso de tecnologias. A cada etapa concluída, a equipe obtinha mais autonomia profissional, acreditando em nós mesmos e que as expectativas sobre melhorias na Educação e sobre o ensino de Matemática poderiam ser atingidas a cada dia.

\section{Referências}

Brasil (2006). Ministério da educação e cultura. orientações curriculares para o ensino médio.

Castro Filho, J. A. d. (2007). Objetos de aprendizagem e sua utilização no ensino de matemática.

Freire, P. (1996). Autonomia da pedagogia: Saberes necessários à prática educativa. São Paulo: Paz e Terra.

Jucá, S. C. S. (2011). A relevância dos softwares educativos na educação profissional. Ciências e Cognição/Science and Cognition, 8.

LEITE, L. S. and SAMPAIO, M. N. (1999). Alfabetização tecnológica do professor. Alfabetização tecnológica do professor, 3:51-76.

Masetto, M. T. (2000). Mediação pedagógica e o uso da tecnologia. Novas tecnologias e mediação pedagógica, 7:133-173.

MISKULIN, R. (2009). As potencialidades didático-pedagógicas de um laboratório em educação matemática mediada pelas tics. O Laboratório de Ensino de Matemática na Formação de Professores. Campinas: Autores Associados.

Perez, G. (2004). Prática reflexiva do professor de matemática. Educação matemática: pesquisa em movimento. São Paulo: Cortez, pages 250-261.

Zimmerman, B. and Schunk, D. (2001). Theories of selfregulated learning and academic achievement: an overview and analysis. in self-regulated learning and academic achievement (pp. 1-37). 